\title{
HOW SHOULD WE RESPOND TO THE CONTINUING FAILURE OF COMPENSATORY EDUCATION?
}

\author{
SALLY POWER \\ School of Social Sciences, Cardiff University, Wales, UK
}

\begin{abstract}
All education systems, to a greater or lesser extent, are marked by educational inequalities. Nearly all education systems, again to a greater or lesser extent, have put in place a variety of 'compensatory' strategies to help reduce these educational inequalities. These strategies have gone through different phases and enjoyed different degrees of support, but have generally been as much a part of the education system as the inequalities they are designed to address.

This paper explores the continuing reinvention and failure of compensatory education strategies. It looks, in particular, at the emergence and limits of recent moves to implement a 'politics of recognition' for schools in disadvantaged areas. It argues that children in disadvantaged schools need a 'politics of redistribution', but that the mechanisms of distribution and the nature of what it is that is to be redistributed are problematic. Drawing on theory and empirical research, the paperconcludes by arguing that, until we have a clearer idea of what it is that we are compensating, compensatory education policies will be doomed to fail.
\end{abstract}

Keywords: Compensatory education, educational inequalities, social injustices, urban education, Bernstein.

\section{Introduction}

At the heart of this paper lies the question 'how should we respond to the continuing failure of compensatory education'? It has been prompted by the mounting evidence that the latest wave of compensatory measures within the UK looks set to be no more successful than earlier interventions. This failure presents a number of challenges to sociologists of education. We know, as Bernstein (1970) famously pointed out over forty years ago, that 'education cannot compensate for society'. However, we also generally reject the stance that attempts to reduce educational inequalities are inevitably futile.

The paper begins with a brief history of the continuing reinvention and failure of compensatory education in the UK and then goes on to look at broad ways in which we might respond to this failure. Drawing on Nancy Fraser's (1997) analytical distinction between economic and cultural injustices, it discusses the relative merits and drawbacks of developing either a simple politics of recognition or a simple politics of redistribution. It identifies the absence of a theoretical basis for compensatory education as a major obstacle to developing an adequate political 
response. The paper concludes by outlining the potential of Basil Bernstein's work for the developing a theoretical approach.

\section{A brief history of compensatory education in the UK}

'Compensatory education' is the term that developed in the UK, borrowed from the USA, during the 1960 s to describe systematic attempts to counter the low educational performance of disadvantaged students. Throughout the first half of the twentieth century, the UK government had already put in place a range of policies designed to promote equality of opportunity in education. These measures included, for example, the 1944 Education Act, which provided free secondary education for all. This Act led to the huge investment in new building programmes and teaching staff. However, by the 1960s it was apparent that while these measures had provided formal equality of opportunity they had not equalized educational outcomes between rich and poor. As Halsey $(1972$, p. 6) bluntly puts it:'the essential fact of the twentieth century is that egalitarian policies have failed.'

The enduring gap between rich and poor presented a major cause for concern for post-war governments who saw it as a remnant of an old class-divided Britain that needed to be more meritocratic if social progress were to be achieved. The crisis in education in particular was highlighted in the influential Plowden Report (Central Advisory Council for Education), published in 1967, which focused attention on the continuing disadvantage experienced by children living in deprived areas. This Report requested not only that the schools serving these areas should be of equivalent standard as those in non-deprived areas, but that they should be 'quite deliberately' made better. It was hoped that a policy of positive discrimination would bring additional resources within the school which could then 'compensate' for the disadvantages of deprivation experienced by the child outside the school.

Following the publication of the Plowden Report, the first major programme of compensatory education began. In England and Wales a number of Educational Priority Areas (EPAs) were identified in the late 1960s. The initiative involved 150 building programmes in 51 local authorities, plus 572 schools that were recognised for giving their teachers special payments for the more difficult teaching conditions. There was also a joint scheme between the (then) Department of Education and Science and the Social Science Research Council to fund a $£ 175,000$ action-research programme in five EPAs. The funds were spent developing and implementing educational initiatives and ensuring rigorous evaluation of their impacts, with a view to developing innovative approaches to the enhancement of educational attainment in socially disadvantaged areas.

The outcomes of the evaluation appeared in successive reports (Halsey, 1972; Midwinter, 1972; Morrison, 1974; Payne, 1974; Barnes, 1975; Lovett, 1975; Smith, 1975) throughout the early 1970 s. These reports are extremely mixed in both their approach and their tone. While some speak positively of instances of good practice or outline general directions that it might be profitable to pursue, demonstrable evidence of any actual improvement in educational outcomes is difficult to find. 
The lack of evidence of impact, together with confusions in the way the policy was framed and implemented (Smith, 1987), led to its collapse as the 1970s progressed. In general, during this period, enthusiasm for compensatory measures and other forms of 'social engineering' waned as the New Right emerged as a political force. The welfare state increasingly became seen as part of the problem and not part of the solution. The language of class differences disappeared. Indeed, Margaret Thatcher claimed it was a 'communist concept'. Differences between people were increasingly viewed as arising from individual and not societal attributes. As Margaret Thatcher famously said in 1987 'there is no such thing as society ... only ... individual men and women.'

Not surprisingly, Conservative governments under Margaret Thatcher and her successor John Major set about the task of dismantling the state apparatus that had made compensatory education possible. This included the abolition of the Inner London Education Authority (as well as the Greater London Council). The power of local authorities was severely limited by the 1988 Education Reform Act which obliged them to devolve the majority of their funds and management responsibilities down to schools. The Act (and subsequent amendments) also provided incentives and encouragement for schools to 'opt out' of their local authority entirely (see Fitz et al., 1993 for an account of this policy).

At the same time as eroding the capacity of the state to 'engineer' social outcomes, the Conservative government promoted the importance of individual entitlements. For example, in 1981 the Government launched the Assisted Places Scheme which enabled academically able children from 'poor homes' to attend elite private schools (see Edwards et al., 1989). It also attempted to stimulate an education market so that 'ordinary' parents could have choice and schools would be forced to respond to consumer rather than professional control. It did this through diversifying provision, removing artificial limits on school enrolment and providing 'performance' data on individual schools (see Gewirtz et al., 1995; Whitty et al., 1998).

Research on the outcomes of these reforms is complex and contested (see Gorard et al., 2003). However, there is general consensus that while they may not have made the situation significantly worse for disadvantaged parents and children, they certainly did not make it better. In general, advantaged children continued to attend advantaged schools and disadvantaged children continued to attend disadvantaged schools.

In 1997, after 18 years in power, the Conservatives were heavily defeated and New Labour came to power. The welfare state and the acknowledgement of classbased inequalities returned - albeit a somewhat different conception of class than that which dominated the earlier period. In Tony Blair's (1999) words, Britain was on the way to becoming a 'one class' country:

Slowly but surely the old establishment is being replaced by a new, larger, more meritocratic middle class ... A middle class that will include millions of people who traditionally may see themselves as working-class, but whose ambitions are far broader than those of their parents and grand-parents. 
The danger was no longer one of class antagonism, but of a small group of families who were excluded from this new meritocratic middle class. Social exclusion involved more than just poverty:

It's a very modern problem, and one that is more harmful to the individual, more damaging to self-esteem, more corrosive for society as a whole, more likely to be passed down from generation to generation, than material poverty. (Blair, 1997)

In order to address this excluded 'underclass', New Labour put in place over the next 10 years a huge array of initiatives targeted at disadvantaged areas and schools. In England, 1998 saw the launch of Education Action Zones (to run alongside Health Action Zones and Employment Action Zones). These were followed in 1999 by the Excellence in Cities policy and Sure Start Local Programmes for the pre-school years, and subsequently by Neighbourhood Nurseries, Early Excellence Centres and Extended Schools. In Wales, there have been interventions such as Communities First, Flying Start for the early years and RAISE for secondary schools. In Scotland, there is the Integrated Community Schools programme. Over the years, some of these policies have been replaced by others and some have been merged together, but the emphasis on targeting extra resources at deprived schools and areas has remained.

As we have written elsewhere (Power et al., 2005), although New Labour's approach to compensatory education interventions shares some of the characteristics of their predecessors, they are also somewhat different. The Table below shows some of the main differences.

Table 1: Contrasting characteristics between early and late compensatory education policies

\begin{tabular}{|l|l|l|}
\hline & Earlier reforms & New Labour Reforms \\
\hline Mode of governance & State bureaucratic & Self-governing partnerships \\
\hline Accountability mechanism & Resources (inputs) & Results (outputs) \\
\hline Time period & Ongoing & Time-limited \\
\hline Identification of areas & Externally-defined & Self-defined \\
\hline Identification of strategies & Top-down & Bottom up \\
\hline
\end{tabular}

In an approach typical of New Labour's 'third way' (Power \& Whitty, 1999), these new programmes are usually governed by partnerships rather than statebureaucracies. For example, each Education Action Zone was run by a forum of business partners, professionals, community and parent representatives. And while the development of earlier programmes was usually measured in terms of how much money had been invested, the new programmes are given performance targets which they have to reach. Funding tends to be temporary - for between 
three and five years - and sometimes dependent on performance. Also, in order to improve commitment from those 'on the ground', the boundaries of the areas, and the strategies which will be put in place, are often defined at the local level. This has led to a 'cocktail' approach of strategies, something which I shall return to later.

While the more responsive formulation of the New Labour reforms may have overcome some of the shortcomings of earlier reforms, the evidence to date suggests that they too have had limited impact. Research I have undertaken with others on the English Education Action Zones policy ${ }^{1}$ (Power et al., 2004) and the Scottish Integrated Community Schools programme ${ }^{2}$ (Sammons et al., 2003) indicates that while some individuals have benefited, there has been little narrowing of the achievement gap. Smith et al. (2007) in their review of the evidence on recent English policies have similarly struggled to find any compelling evidence of an improvement in educational outcomes. As they point out:

'The evidence on impact suggests at best modest gains, and this at a time when the economy has been improving in ways that have reached through to some of the most disadvantaged parts of Britain.' (Smith et al., 2007, p. 147).

That this lack of impact is not unique to the UK, or to New Labour, is supported by the evidence being complied across Europe as part of the EUROPEP project (Demeuse et al., 2008).

\section{Responding to the ongoing failure of compensatory education}

How we respond to the failure of compensatory education will depend on the nature of inequalities which disadvantaged children and their schools experience. In thinking about these inequalities, I want to draw on the Nancy Fraser's (1997) very useful distinction between economic injustices and cultural injustices. Although, as Fraser herself acknowledges, these different injustices rarely exist in their 'pure' forms, there are heuristic advantages in disentangling them.

\section{Economic injustices involve:}

1 Education Actions Zones (EAZs) were launched in England in 1998 and ran for five years. They were run by a small number of 'partners' including local authority, business, voluntary sector and community representatives and involved up to 25 schools. They were later subsumed within the Excellence in Cities policy. For an overview of the main findings from our ESRC-funded research on the policy, see Power et al. (2004).

2 The Integrated Community Schools programme (formerly called the New Community Schools programme) was launched by the then Scottish Office in 1998. The 37 NCS projects in the pilot programme involved over 170 schools or institutions in 30 education authorities. Some projects were single schools but most comprised clusters of associated schools. The pilot was due run for three years. However, before it was finished the Scottish Executive announced in 2001 that the programme was to be 'rolled out' to all Scotland's' schools. For the main findings of our SEEDfunded research on the policy, see Sammons et al. (2003). 
- Exploitation (having the fruits of one's labour appropriated for the benefit of others)

- Economic marginalisation (being confined to undesirable, poorly paid work - or having access to none)

- Deprivation (being denied an adequate material standard of living)

Cultural injustices, on the other hand, include:

- Cultural domination (being subjected to patterns of interpretation and communication that are associated with another culture and are alien and/or hostile to one's own)

- Non-recognition (being rendered invisible by means of ... authoritative representational, communicative, and interpretative practices ...)

- Disrespect (being routinely maligned or disparaged in stereotypic public cultural representations and/or in everyday life situations.)

Fraser illustrates the distinction through an analysis of what she sees as the different issues faced by 'exploited classes' and 'despised sexualities'. She argues that the working class suffers the economic injustices of exploitation, marginalisation and deprivation and that their disadvantaged position is determined by, indeed is defined by, the political and economic structure of society. Although members of the working class may also suffer cultural injustices, Fraser suggests that these usually arise from the material hardships they experience. According to Fraser, it therefore follows that to alleviate these injustices; a politics of redistribution is required. This may include, among other things, redistributing income, changing the division of labour etc.

The situation of the working class is contrasted with that of gays and lesbians, who, Fraser contends, suffer cultural injustices. They live in a largely heterosexist society in which their own sexuality is either rendered invisible or routinely maligned. Although this may have material consequences, Fraser argues that, unlike the working class, they need a politics of recognition rather than redistribution. This may involve positive affirmation of gay and lesbian relationships, challenging the homo-hetero dichotomy, etc.

From Fraser's analysis it becomes clear that not all injustices are of the same order and that different forms of injustice require different remedies. The question for us to consider is whether disadvantaged students and schools suffer from an economic or a cultural injustice.

\section{The cultural injustice behind educational failure}

If we go back to Fraser's definition, we can certainly see that the disadvantaged do suffer from cultural injustices. For instance, ethnic minority communities can be seen to suffer from cultural domination. They are subjected to the patterns of 
interpretation and communication of another culture - and one which is often alien and hostile to their own. These communities, and the schools they attend, are also often treated with disrespect. They are routinely disparaged in stereotypes in the media and in everyday representations.

Some sociologists (eg Keddie, 1973) goes so far as to suggest that it is not only that we have deficit views of disadvantaged communities but that our definitions of curriculum, intelligence and behaviour are all culturally relative and are thus arbitrarily imposed by the dominant onto the dominated. The imposition of these inappropriate frames of reference, rather than any attributes of the disadvantaged, becomes the source of educational inequality.

If we see the source of the problem of educational failure as being located in cultural domination then it is possible that programmes of compensatory education actually exacerbate the injustice. This kind of critique is reminiscent of earlier critiques of compensatory education, in particular that made most powerfully by Basil Bernstein (1971, p. 192) in his famous paper 'Education cannot compensate for society':

The concept 'compensatory education' implies that something is lacking in the family, and so in the child. As a result the children are unable to benefit from schools. It follows then that the school has to 'compensate' for the something which is missing in the family and the children become little deficit systems.

Certainly, Smith (1987) subsequently argued that one reason for the demise of the EPAs was the lack of a coherent conceptualisation of disadvantage which led to the 'internal collapse' of the policy. In particular, he criticised the tendency to emphasise the 'worst' features of EPAs which led to a perception that disadvantage was attributable to familial and individual pathologies.

The more recent reforms are also underpinned by deficit notions of the inner-city communities and their inhabitants. For example, an analysis of how disadvantaged parents are represented in Education Action Zone applications reveals many instances of negative portrayals (Power \& Gewirtz, 2001). For example, one comments that '... the norm is where pupils have been brought up in families dependent on benefits from the government'. The dysfunctionality of these families is revealed through 'an apparent lack of male role models' and a 'climate of indiscipline'. The bids describe how'domestic violence and abuse are two common features of every day life within the housing estates', where 'many parents do little to ensure their children ... subscribe to basic norms of behaviour'.

It is possible to argue, therefore, that compensatory education compounds the difficulties of those living in disadvantaged areas through further contributing to their cultural injustices. What is needed is a politics of recognition. 


\section{A politics of recognition for disadvantaged children and schools}

The argument that disadvantaged children need a politics of recognition is nothing new. Many educationalists in the 1960 s and 1970 s tried to counter what they saw as negative and deficit representations of the disadvantaged with more positive appreciation of their lives and culture. The following statement from an American speech significantly entitled 'Strengths of the inner city child' (my emphasis) by Leon Eisenberg (1973, p. 245) is fairly typical of the position taken in this period:

The key issue in looking at the strengths of the inner city child is the importance of not confusing difference with deficit. Any teacher who has taught a grade in the middle-class section and a grade in the lower-class section of the city can certainly testify to the difference. Inner city children's clothes, their accents, their activity level, their classroom behaviour, their type of verbalisation, their health standards, all do differ.

However, in the UK we are recently seeing the emergence of a new kind of politics of recognition. It is a politics of recognition that has been called for by many involved in education to counter the crude ranking of schools within the education market place. Over the last twenty years schools in England have been compelled to publish their students' results at various stages. These results are then used to compile 'league tables' of performance. There have been many complaints that these tables fail to take into account contextual differences between schools. Moreover, these tables do not recognise that different schools may have different priorities. The critics argue that these tables themselves constitute a form of injustice.

Table 2: 'Improving Schools' league table

\begin{tabular}{|l|c|c|c|c|c|}
\hline Name & $\begin{array}{l}1997 \text { GCSE } \\
\text { result (\%)* }\end{array}$ & 1997 rank & $\begin{array}{c}1996 \text { GCSE } \\
\text { result (\%) }\end{array}$ & 1996 rank & Rise \\
\hline $\begin{array}{l}\text { Harris City Technology } \\
\text { College, London }\end{array}$ & 64 & 37 & 27 & 74 & 37 \\
\hline $\begin{array}{l}\text { Archbishop Temple } \\
\text { School, Preston }\end{array}$ & 57 & 44 & 22 & 79 & 35 \\
\hline $\begin{array}{l}\text { Bowland County High } \\
\text { School, Clitheroe }\end{array}$ & 58 & 43 & 26 & 75 & 32 \\
\hline
\end{tabular}

*Percentage of pupils gaining at least 5 GCSEs at grades $A^{*}$-C.

Source: 'Improving Schools' http://news.bbc.co.uk/1/hi/special report/ education league tables/32677.stm

In order to counter this injustice, the New Labour government, and some academics, have sought to develop alternative league tables. For example, from 1998, the English Government published an 'Improving Schools' league table. The 
following table contains the results of the 'winners' of the first of these new kinds of league table.

The school at the top of the table, Harris City Technology College, has seen a 37 point rise in its ranking as its GSCE results have increased from 27\% in 1996 to $64 \%$, in 1997 - a larger increase than any other school in England. The second school, Archbishop Temple, has seen an improvement of 35 points - with $22 \%$ of students obtaining the standard GCSE result in 1996 and 57\% achieving it in 1997. It is clear from this table that schools with very high levels of attainment cannot be rewarded, because they have less scope for improvement. The table is a reverse of conventional performance tables in as much as it is only those schools that usually are consigned to the bottom of the league that are able to appear at the top of this table.

Since 2004, there have also been a number of other tables which have based rankings on 'value-added' measures. These measure, not the final result, but how much the progress has been made by pupils as they move from one stage to another.. Sometimes other weightings are put in to allow for contextual disadvantage. These alternative tables are then reported to celebrate the achievements of disadvantaged schools. The extract, called 'Hidden Triumphs' (Crace, 2006) below is taken from a Guardian newspaper report on a school which does badly in a conventional performance league table, but well in a value-added league table:

You wouldn't know the corridors were painted only a few months ago. Damp stains have already appeared on the ceilings and the walls are peeling ... King Richard secondary school in Portsmouth is falling apart. Literally. It was built in the late 1940s and should have been knocked down 10 years ago ...There again, the school blends in with its surroundings. King Richard is in the heart of Paulsgrove, a run-down working-class estate on the northern edge of the city ... Everything about Paulsgrove screams low expectations. Check out the government's GCSE school league tables and King Richard seems to fall in line with the neighbourhood. In 2005, 46\% of its pupils achieved five or more passes at $A^{*}-C$, bang on the average pass rate for Portsmouth ... but 10\% down on the rest of England. Yet research published today ... shows that King Richard is doing a great deal better than these figures suggest. ... and has thus significantly outperformed expectations.

However, a politics of recognition which turns failure into success in this way is potentially very dangerous. Recognising that schools have to educate children in difficult conditions, and that some schools are better at it than others, may make the teachers working in them feel less stigmatised but will do nothing to tackle the underlying causes of educational failure. Indeed, at its extreme end, such a politics of recognition may end up celebrating the experience of exploitation, marginalisation and deprivation. This kind of politics of recognition is also dangerous because it 'naturalises' the failure of the disadvantaged. These alternative league tables tell 
the government and teachers that these schools are doing the best, or better, than can be expected in the circumstances.

What is needed is a politics that tackles rather than simply recognises the circumstances. For example, it is not just as Eisenberg would have us believe that the health standards of the 'inner-city' child differ, it needs to be acknowledged that they are worse. The issue is one of deficit. However, this does not mean, though, that the poor are responsible for these deficits. The identification of deficits constitutes a condemnation of economic exploitation and injustice. And this inevitably brings us back to the need for politics of redistribution within education - but one which does not repeat shortcomings of previous and current interventions.

It is not enough just to assert that we need a politics of redistribution. It is easy for sociologists simply to point out a general direction without being specific. We also need to clarify what it is we are redistributing, how and to whom. In order to do this we need to have a much clearer conceptualisation of what compensatory education is trying to do. The lack of a strong theoretical base has contributed to the lack of a solid empirical base. While there are many evaluations of different interventions, but they have not accumulated into a coherent account of the processes and problems of compensatory education. The absence of coherence in terms of how we frame compensatory strategies has also been exacerbated by the move towards a 'what works' approach. Although the underlying research evidence for any particular strategy 'working' is usually fairly weak, the piecemeal implementation of 'good ideas' has led to a huge mushrooming of different kinds of interventions underpinned by quite different - and sometimes contradictory change mechanisms. At times this diversity of approaches has even been seen as potentially advantageous in itself. For example, when the Education Action Zones policy was launched, a government minister talked favourably of the benefits of a 'cocktail' approach and drew parallels with the multiple medications that are most successful in treating HIV/AIDS (fieldnotes, 1999). While there may (or may not) be practical merits in this approach, it makes the systematic exploration of the efficacy of the different elements impossible.

In order to cut through this chaos, we need an analytical framework which will help us grasp both the complexity, but also the underlying principles, of different interventions. In the next section, I will briefly outline some ideas I am developing with Geoff Whitty (Power \& Whitty, 2008) which we think can be used to compare and contrast different approaches to compensatory education with a view to exploring their relative potentialities for improving the educational experiences of disadvantaged pupils.

\section{A Bernsteinian analysis of compensatory education}

While Bernstein's (1971) critique of compensatory education is as powerful now as it was nearly forty years ago, we believe that his theoretical understanding of educational transmissions $(1971,1977,1990,1996)$ can provide a fruitful starting 
point for thinking about how to make compensatory education more effective than it has been so far. It enables us to move beyond a simple politics of recognition or redistribution.

Bernstein's analysis of education is, as is widely acknowledged, highly structural in that it is concerned to make visible the underlying grammar of educational transmissions. Through his work he has attempted to address what he sees as a major failing within the dominant theories of cultural reproduction - the absence of a theory of pedagogic discourse. Within these theories, education and schools are little more than channels for external power relations. It is, he argues, 'a matter of great interest that the actual structure which enables power to be relayed, power to be carried, is itself not subject to analysis.' (Bernstein, 1996, p.18) What we need is more analysis on the structure of the relay and less on what is that is being relayed. The two concepts at the root of his analysis, and the ones which will inform the analysis, are those of classification and framing. Classification reflects the distribution of power and the principles by which boundaries are established between categories. These categories might relate to agencies, agents, discourses or practices. Strong classification is underpinned by the rule that 'things must be kept apart'. Weak classification must be underpinned by the rule that'things must be brought together'. Classification determines the metaphoric structuring of space. Framing, on the other hand, reflects the distribution of control over communication. It can refer to the relations between parents and children, between teachers and pupils and between teachers and parents. Strong framing is where the transmitter has explicit control over the communication; weak framing gives the acquirer more apparent control over the communication.

Strategies of compensatory education are, at their root, nearly always about re-ordering these principles. They seek to strengthen some aspects and weaken other aspects of the relationship between the neighbourhood, the family, the child and the school. However, they do so in differing directions. In the following section, examples of strategies implemented in recent reforms in the UK have been categorised in terms of the extent to which they alter the classification and framing relations between the school and the home.

\section{Interventions with strong classification and strong framing}

Some of the strategies designed to 'compensate' for educational disadvantage can be categorised as being strongly both classified and framed, in that they do not attempt to weaken the strong boundaries between home and school nor to weaken communicative control of the pedagogy. Indeed, they may even strengthen classification and framing at the level of the primary school in particular. These strategies generally involve giving students and their families in disadvantaged schools more education - more intensive teaching programmes, more teaching materials, more teaching assistants. These activities may be directed at the child, the family or the broader community. The following activities (and others listed in the paper) are examples of initiatives that have been implemented in the Education 
Action Zones initiative in England and the Scottish Integrated Community Schools programme. Examples of these activities have included:

The purchase of literacy \& numeracy games packs;

Reading recovery programmes

Establishing a maths library in the school

In all these activities, there is a clear boundary between the specialist and the learner. There is no blurring of the boundary between educational knowledge and everyday knowledge. It is clear both what is being imparted and how it will be evaluated.

They may be some altering of the temporal boundaries between school, home and community, between school time and after-school time, between term time and holidays. There may also be some altering of the boundaries between home and school - with parents and community members being encouraged to come into the school for classes and moves to take the 'school' into the home. However, while the location boundary may have altered, the strength of classification between school knowledge and everyday knowledge remains unchanged. There is always a strong division of labour. It may become more complicated within the school for example with the introduction of teaching assistants, but the demarcation of responsibility is clear and hierarchical within the classroom.

\section{Issues and implications}

To some extent, this form of intervention represents a classic politics of redistribution. There are clearly a number of potentially positive impacts arising from giving pupils, parents and the community 'more' schooling. In some ways it could be argued that providing more intensive lessons and better resources is the only way to tackle the inadequate educational experience which poor and disadvantaged pupils have experienced hitherto. These extra resources will bring them a little closer to the kind of provision from which more advantaged students benefit.

However, while some individuals may benefit from these programmes, it is hard to see how they can provide a systemic solution. Firstly, the scale of the redistribution which would be needed to provide poor and disadvantaged schools with sufficient resources to compensate for current financial injustices both in the home and in the school would be enormous.

Secondly, it seems unlikely that a solution based just on giving students more of the very kinds of activities at which they are failing is likely to work. As Bernstein argues, it is the strong classification and framing of pedagogy which gives the middle class its advantages in the first place. Indeed, he claims that the 'strong classification between family and school is a product of the symbolic power of the middle class family' (1996, p. 106-7). Because middle class children have been prepared from an early age to distinguish the difference between home and school 
they are more likely to have access to the distinctive recognition and realisation rules which the school context demands. Unless disadvantaged pupils have access to these rules as well they will always be at least one step behind. Simply increasing the frequency and intensity of educational activities demands is hardly going to transform failure into success.

\section{Interventions to weaken classification and weaken framing}

By contrast, there is a range of strategies which seek to address educational disadvantage not through giving parents and students 'more' schooling but through weakening the strength of classification between the school, the home and the community and the framing of the relationship between the teacher or expert and the parent and child.

The weakening of boundaries can occur within the curriculum and in the relationship between the school and the community. On the curriculum front, and as Bernstein identified, there are moves towards an integrated curriculum for those deemed to have learning difficulties. Schools have introduced activities such as Youth Theatre Groups or local community arts projects.

For these students, who are likely to fail performance-related tasks, there are moves towards 'personalising' achievement in ways which will celebrate 'competence'. The competence model is evident in the moves towards'Personalised learning plans'.

Like the strongly classified and framed strategies, these strategies can also emphasise the expressive domain, but here the approaches are more therapeutic. They may involve some form of self-reflection and self-realisation. Relations are likely to be less hierarchical. The role of fellow pupils is emphasised e.g.:

Peer education

Buddy support scheme

Physical boundaries between the inside and the outside of the school are weakened. School space can be used by parents - without the purpose having to be classified as explicitly 'educational' e.g.:

In-school family room \& drop in facilities

Parents' room, lending library and PC/internet

Indeed, there may be moves to'democratise'schools through consultations with pupils, parents and the wider community, e.g.:

Creation of parent forum

Consultation with parents on curriculum \& school ethos 
In some ways these strategies are reminiscent of the earlier moves towards the 'community education' programmes of the 1970s which were built on a politics of recognition. These strategies were, to some extent, a reaction against the 'deficit' perspective embodied within some forms of compensatory education. It is not that the disadvantaged pupil and their family are 'lacking' (and therefore do not need to be given 'more'). They are disadvantaged by a middle class education system which fails to recognise different and distinctive cultures.

\section{Issues and implications}

If maintaining or strengthening the classification and framing between home and school is likely to do little to reduce educational disadvantage, then it might be argued that breaking down these barriers and building more inclusive relations can only prefigure a greater mutual understanding.

But, while Bernstein, in his critique of compensatory education, argues 'the contents of the learning in school' should be drawn much more from the child's experience in his (sic) family and community $(1971$, p. 192), the idea that simply weakening boundaries will of itself make a significant difference is both empirically and theoretically difficult to sustain.

There is already significant evidence to suggest that weakening the classification and framing of pedagogies does not, on its own, enhance the learning of disadvantaged pupils. Indeed, there are some indications that the invisibility of the rules which are implicit in integrated curricula actually makes the acquisition of recognition and realisation rules harder (Sharp \& Green, 1975; Daniels, 1995).

In part this is because this weakening of classification and framing is relatively superficial, in as much as the underlying distribution of power and principles of control remain unchanged.

Indeed, their invisibility renders the authority of the teacher and the school less open to challenge. It is more probable, therefore, that simply weakening the classification and framing without changing or challenging the underlying distribution of power and control will achieve little.

Moreover, even if there were to be a more thoroughgoing 'opening' of the school so that the local community became the source of educational change that the community education pioneers of the 1970s envisaged, it is unclear whether this would significantly increase the relative advantages of the disadvantaged pupil. The equivalent valuing of different cultures now seems strangely naïve and misguided. And although Bernstein might have argued for greater connection between school knowledge and everyday knowledge, it is not entirely clear what he meant by this. While noting the many shortcomings of schools, he was probably not arguing for the collapsing of the distinction between home knowledge and school knowledge. Indeed, even in his early New Society article (Bernstein, 1970), he argued that education must involve the introduction of children to the universalistic meanings of public forms of thought. 


\section{Interventions with weak classification but strong framing}

In some ways the two preceding categories of strategies are reminiscent of earlier compensatory education reforms. The first is based on an old-fashioned politics of redistribution, the second on an old-fashioned politics of recognition. What we are seeing very strongly in the more recent initiatives, though, is a growth in strategies where the classification is weak - in that boundaries between the school, the family and the community are blurred - but the control over the communication is very strong.

Within the school, there are a range of schemes which are aimed at changing student behaviour - not through the imposition of explicit pedagogies and targets as in the $\mathrm{C}+\mathrm{F}+$ strategies or the weakening of the boundaries of the C-Finitiatives. The boundaries between areas and activities are weakened as the focus encompasses the whole child, but the pedagogy is very strong. For the pupil, there can be intensive programmes and activities designed to change behaviours:

Develop existing SPIN (effecting change/communication problems) and fast track (developing social competence) initiatives

Activity based, team-building group work for poor attenders

For the family and the community, there is a whole array of schemes designed to 'improve' parental competence. In line with proposals to introduce 'super nannies' into deprived areas, many compensatory education programmes provide courses such as the following:

\section{Assertiveness \& anger management for parents Positive Parenting Programme Men's parenting group}

These programmes and courses are weakly classified in as much the boundary between everyday knowledge and school knowledge is dissolved, but strongly framed because they are underpinned by a clear power relationship between the expert and the learner. The pedagogy is highly visible, with the teacher/expert having techniques that the pupil or parent must learn.

\section{Issues and implications}

At first sight, this type of intervention looks to have a lot of potential. It brings the everyday knowledge of the family context and pupil experience into the educational domain but it does not hide the power relations between teacher and taught. It is very explicit about the required recognition and realisation rules. However, it is also deeply problematic. The strong framing theoretically enables the everyday to be developed into the esoteric, the context-dependent into the abstract, the horizontal discourse into the vertical discourse. But there is no esoteric, 
abstract or vertical knowledge within it - or at least not as currently developed. It is empty of knowledge content - or at least the kind of knowledge that will enable disadvantaged pupils to have access to the forms of knowledge available to advantaged children.

Indeed, these interventions are often based on recontextualised forms of behaviourist and therapeutic psychology which are predicated on very strong deficit theories of disadvantaged homes. While the explicitness of the framing potentially renders the authority of the school open to challenge so that it has continually to justify and legitimise its authority, the messages being transmitted within this relay render any such challenge symptomatic of pathological socialization. As currently constituted, these types of interventions are about pedagogising the whole child and even the family.

Whether this kind of intervention could have more radical potential if it were based on different assumptions or on a different recontextualisation of knowledge is difficult to know. Some might argue that the combination of weak classification and strong framing could be used for the purpose of illuminating the nature of social reality, history and culture. For this to happen, though, there would need to be some radical revisioning of the knowledge base of education.

\section{Interventions with strong classification but weak framing}

We have not so far characterised any compensatory education initiatives as involving strong classification and weak framing, partly because they are difficult to identify in current initiatives. Yet this is perhaps what our critique of other approaches points to. The weakening of the control over the communication may allow connections to be made between pupils' experience and the curriculum, but as a means to introducing them to the abstract forms of thought and universalistic knowledge. There is already considerable evidence that actually making those connections has proved highly problematic for many pupils, and indeed their teachers, not least because using the different discourses entails acquiring different recognition and realisation rules (Whitty et al., 1994). However, difficult as it may be, articulating the connections and disconnections between home and school must be worth exploring more consistently.

Clearly, this is only the beginning of an analysis using the concepts of classification and framing, but one we think that has some potential. Of course education cannot compensate for society in any simple way. But that does not mean that educators should accept the continuing failure of the disadvantaged as an inevitability. While Bernstein's analysis shows us the intractability of the relationship between knowledge, schooling and inequality, it also provides a way of thinking about what would need to be put in place if that relationship were to be interrupted. 


\section{Conclusion}

This paper began with the question of how we should respond to the continuing failure of compensatory education. It was been prompted by the mounting evidence that the latest wave of compensatory measures within the UK looks set to be no more successful than earlier interventions. Moreover, the UK experience looks no different from that elsewhere.

One strategy is to replace a failed politics of redistribution with a politics of recognition. However, while current reforms, like their predecessors, do embody deficit representations of disadvantaged children, families and communities, more positive re-evaluations of disadvantage are at best futile and at worst dangerous. In particular, there must be serious concerns about the new politics of recognition which has emerged in the UK and which presents educational failure as educational success.

We need to develop a more creative response - and one which has a much stronger theoretical basis. I have attempted to outline one potential way of developing a theory of compensatory education through drawing on the theories of Basil Bernstein. It is far too early to predict whether this is the most appropriate framework - or whether it will have any purchase on policy and practice. However, it is not too early to predict that without an adequate conceptualisation of what we are trying to do, future attempts to offer disadvantaged children a more fruitful educational experience will be doomed to fail.

\section{Acknowledgements}

This paper is a slightly revised version of a keynote address given at the conference Education, Equity and Social Justice, Charles University, Prague, 16-19 June 2008. I am grateful to Dr David Greger for organizing the conference and for inviting me to present. I would also like to acknowledge the support of the Institut Nationale de Recherche Pedagogique and, in particular, Dr Daniel Frandji, for the support which enabled me to develop this work in Lyon, France.

\section{References}

Barnes, J. (1975). Educational Priority. Vol 3. Curriculum Innovation in London's EPAs. London: Her Majesty's Stationery Office.

Bernstein, B. (1970). 'Education cannot compensate for society', New Society, 26 February 1970, 344-47.

Bernstein, B. (1971). Class, Codes and Control Volume 1, London: Routledge and Kegan Paul.

Bernstein, B. (1977). Class, Codes and Control Volume 3, $2^{\text {nd }}$ edition, London: Routledge and Kegan Paul. 
Bernstein, B. (1990). The Structuring of Pedagogic Discourse, London: Routledge.

Bernstein, B. (1996). Pedagogy, Symbolic Control and Identity, London: Taylor and Francis.

Blair, T. (1997). Speech given at Stockwell Park School, Lambeth at launch of Social Exclusion Unit. 8 December.

Blair, T. (1999). Speech delivered 14 January, IPPR. www.number-10.gov.uk

Central Advisory Council for Education (England) (1967). Children and their Primary Schools, London: Her Majesty's Stationery Office. (The Plowden Report)

Crace, J. (2007). 'Hidden Triumphs', The Guardian, November $7^{\text {th }}$.

Daniels, H. (1995). 'Pedagogic Practices, Tacit Knowledge and Discursive Discrimination: Bernstein and Post-Vygotskian Research', British Journal of Sociology of Education, 16 (4), 517-32.

Demeuse, M., Frandji, D., Greger, D., \& Rochex, J.-Y. (Eds.) (2008). Evolution des politiques d'éducation prioritaire en Europe. Conceptions, mise en śuvres, débats. Lyon: Institut Nationale de Recherche Pédagogique.

Edwards, T., Fitz, J., \& Whitty, G. (1989). The State and Private Education: An Evaluation of the Assisted Places Scheme. London: Falmer.

Eisenberg, L. (1973). 'Strengths of the inner city child', In J. Raynor and J. Harden (Eds), Cities, Communities and the Young: Readings in Urban Education Volume 1. London: Routledge and Kegan Paul.

Fitz, J., Halpin, D., \& Power, S. (1993). Grant Maintained Schools: Education in the Market Place. London: Kogan Page.

Fraser, N. (1997). 'From Redistribution to Recognition? Dilemmas of Justice in a "Postsocialist" Age', In N. Fraser Justice Interruptus, New York : Routledge.

Gewirtz, S., Ball, S. J., \& Bowe, R. (1995). Markets, Choice and Equity in Education. Milton Keynes: Open University Press.

Gorard, S., Taylor, C., \& Fitz, J. (2003). School, Markets and Choice Policies. London: RoutledgeFalmer.

Halsey, A. H. (1972). Educational Priority. Vol 1. EPA: Problems and Policies. London: Her Majesty's Stationery Office.

Keddie, N. (1973). Tinker, tailor...the myth of compensatory education, Harmondsworth: Penguin.

Lovett, T. (1975). Adult Education, Community Development and the Working Class. London: Ward Lock Educational.

Midwinter, E. (1972). Priority Education. Penguin: Harmondsworth.

Morrison, C. M. (Ed.). (1974). Educational Priority. Vol 5 . EPA: A Scottish Study. Edinburgh: Her Majesty's Stationery Office.

Payne, G. (1974). Educational Priority. Vol 2. EPA: Surveys and Statistics. London: Her Majesty's Stationery Office.

Power, S., \& Whitty, G. (1999). New Labour's Education Policy: First, Second or Third Way?, Journal of Education Policy, 14 (5) 535-546.

Power, S., \& Gewirtz, S. (2001). Reading Education Action Zones, Journal of Education Policy 16 (1) 39-51 
Power, S., \& Whitty, G. (2008). 'A Bernsteinian Analysis of Compensatory Education', Paper presented at the $5^{\text {th }}$ Basil Bernstein Symposium, Cardiff University, July $9^{\text {th }}$ $12^{\text {th }}$.

Power, S., Rees, G., \& Taylor, C. (2005). New Labour and Educational Disadvantage: the Limits of Area-Based Initiatives, London Review of Education 3 (2) 101-116.

Power, S., Whitty, G., Gewirtz, S., Halpin, D. and Dickson, M. (2004). Paving a "Third Way"? A policy trajectory analysis of education action zones, Research Papers in Education, 19 (4) 453-476

Sammons, P., Power, S., Elliot, K., Robertson, P., Campbell, C., \& Whitty, G. (2003). Key Findings from the National Evaluation of the New Community Schools Pilot Programme in Scotland. Edinburgh: Scottish Executive

Sharp, R., \& Green, T. (1975). Education and Social Control. London: Routledge and Kegan Paul.

Smith, G. (1975). Educational Priority. Vol 4. EPA: The West Riding Project. London: Her Majesty's Stationery Office.

Smith, G. (1987). 'Whatever Happened To Educational Priority Areas', Oxford Review Of Education, 13 (1) 23-38.

Smith, G., Smith, T., \& Smith, T. (2007). 'Whatever happened to EPAs? Part 2: Educational Priority Areas 40 years on', Forum 49 (1\&2) 141-156.

Thatcher, M. (1987). Interview for Women's Own, Sep 23rd, Archived within the Thatcher Archive, 10 Downing Street, London.

Whitty, G., Power, S., \& Halpin, D. (1998). Devolution And Choice In Education, Buckingham, Open University Press.

Whitty, G., Rowe, G., \& Aggleton, P. (1994). Subjects and themes in the secondaryschool curriculum, Research Papers in Education, 9(2), 159-181. 